\title{
As masculinidades da nossa América*
}

\section{Betina Warmling Barros**}

Por qual razão uma teórica feminista deveria dirigir sua produção para os estudos das masculinidades? É com esse questionamento que Mara Viveros Vigoya inicia sua mais recente obra As cores da masculinidade: experiências interseccionais e práticas de poder na Nossa América (2018). A autora, antropóloga colombiana e professora titular na Universidade Nacional da Colômbia, possui uma extensa produção nos Estudos de Gênero Latino-americanos. Ademais, pelo menos desde 2002, vem desenvolvendo pesquisas sobre homens, masculinidades $e$ relações de gênero na Colômbia, temática que se materializa nessa obra, na qual Vigoya se dirige aos homens e fala sobre eles "com uma voz feminista que os desafia, mas sem diminuí-los" (p. 21).

Ao localizar o gênero masculino nos paradigmas de raça $e$ classe, a interseccionalidade se torna um pilar para a pesquisa da autora, pois permite pensar as relações de dominação como um processo complexo e contraditório (p. 23). É, portanto, muito a partir dos caminhos teóricos já construídos por R. W. Connel que a autora produz suas próprias conclusões sobre as masculinidades no continente latino-americano. Aliás, é também a socióloga australiana a responsável pelo prefácio do livro, oportunidade na qual exalta a apresentação realizada por Viveros do panorama das pesquisas sobre masculinidades por toda a Nuestra América denominação utilizada pela autora colombiana como forma de

* Recebida em 22 de março de 2019, aceita em 30 de abril de 2019. Resenha de: VIGOYA, Mara Viveros. As cores da masculinidade: experiências interseccionais e práticas de poder na Nossa América. Rio de Janeiro, Papeis Selvagens, 2018.

** Doutoranda em Sociologia na Universidade de São Paulo. São Paulo, SP, Brasil. bbarros@usp.br / https://orcid.org/0000-0001-6180-5652 
reconhecer as lutas pela reapropriação e ressignificação da nossa identidade continental (p. 29).

As cores a que faz referência o título do livro pretende nomear não somente as diversas cores de pele, mas também gêneros e sexualidades que organizam as experiências dos homens colombianos. Para a autora, trata-se de uma sociedade "pigmentocrática", na medida em que a racialização atravessa fronteiras de classe e incorpora as diferenças socioeconômicas (p. 24). A obra, portanto, externaliza uma preocupação com as normas da masculinidade que se impõem a todos os homens sob a forma de mandados comportamentais e morais, buscando, mais especificamente, dar conta da experiência de gênero de alguns homens na Colômbia a partir do seu conhecimento sobre essa experiência e das interpretações situadas da própria autora.

Em uma primeira parte, são abordados os pressupostos $e$ vazios da teoria feminista para compreender a dominação masculina, seja pela revisão dos estudos sobre masculinidades na literatura em inglês e em francês (primeiro capítulo), seja através da forma como se aborda o problema na Nossa América (segundo capítulo). Na segunda parte, a autora adentra nas masculinidades nossamaericanas através dos estereótipos existentes sobre a sexualidade masculina na Colômbia (terceiro capítulo), das continuidades e descontinuidades históricas da branquitude (quarto capítulo) e, finalmente, das transposições entre violência estrutural e violência simbólica na Nossa América (quinto capítulo).

Procurando ultrapassar alguns binarismos postos pelo debate feminista norte-americano, a autora inicia relembrando que, se os primeiros estudos com ênfase na dimensão relacional do conceito de gênero ainda davam mais atenção às mulheres, os chamados men's studies se estabeleceram a partir de duas orientações: como aliados do feminismo ou como autônomos. Cecchetto também se ateve à tentativa de revisar as produções desse campo de estudos e conclui que parte da literatura vinculada aos men's studies traz a marca do paradigma exclusivo do papel sexual, fortemente associado ao legado funcionalista $e$ 
baseada em supostas dicotomias ontológicas dos homens $e$ mulheres (2004:37).

Em contraponto, surge um modelo que contesta o esquema rígido dos papeis e propõe a absorção da noção de masculinidade hegemônica, de autoria de $\mathrm{R}$. W. Connell ${ }^{1}$, para quem o "gênero é uma forma pela qual a prática social é ordenada" e a masculinidade são "configurações de prática" (1995:71). Rompe-se com a ideia de que a masculinidade é uma qualidade estática $e$ inaugura-se a ideia de que é uma manifestação histórica. A masculinidade hegemônica, então, seriam as práticas de quem pretende assegurar o patriarcado e a dominação dos homens sobre as mulheres (Connell, 1995:77).

Sobre os estudos da língua francesa, Viveros concede especial destaque à obra de Bourdieu, $A$ dominação masculina (1998), tecendo críticas às imprecisões na ideia de que o amor seria uma trégua a essa dominação; e aos Cahiers d'études africaines que contemplam artigos sobre as masculinidades no continente africano (p. 49). Em seguida, a autora se dedica a exaltar a importância do chamado Black Feminism para os estudos da masculinidade, sobretudo pela oposição à essencialização dos homens por sua condição biológica.

Ao concluir, a autora entende que os estudos sobre masculinidades iniciam na década de 70, mas é apenas na década de 90 que esse novo campo de estudos acadêmicos se consolida (p. 57). Na visão de Kimmel (2008) retomada, existem dois argumentos para justificar esse novo campo: a) a necessidade de questionar e transformar os mecanismos que criam a masculinidade; b) a importância de entender que os homens não necessariamente se sentem poderosos. Viveros aproveita para traçar um paralelo entre essa distinção $e$ aquilo que Fabre e Fassin (2003) intitularam de dominação masculina "tradicional" $e$ "reacionária". Para essa última, a dominação masculina não se

${ }^{1}$ Cecchetto identifica Connell como Robert, nome de batismo da socióloga australiana. Contudo, em suas obras mais recentes, após passar por um processo de transição de gênero, a autora passa a se identificar como Raewyn Connell ou R. W. Connell, que é a forma utilizada por Viveros em seu livro. 
funda sobre a desigualdade sexual e tampouco sobre a perpetuação de uma ordem patriarcal, mas se define como uma "reação" ao questionamento dessa ordem pelas reivindicações de liberdade do feminismo e do movimento gay e lésbico. É, portanto, um movimento de ressaca.

Já num segundo eixo de trabalhos a partir da década de 1980, incorporam-se as contribuições do feminismo, com especial atenção para a chamada "crise da masculinidade". Na revisão bibliográfica realizada pela autora, destacam-se os seguintes temas e sua representatividade no conjunto das pesquisas sistematizadas: a) identidades masculinas (30\%); b) masculinidades e violência $(18 \%)$; c) saúde dos homens (16\%); d) afetos e sexualidades (14\%); e) reflexões epistemológicas (14\%); f) representações e produções culturais (6\%); g) espaços de homossociabilidade masculina (2\%).

Vigoya ressalta que mesmo nas pesquisas sobre identidades masculinas, foram realizadas análises sobre as relações de poder institucionalizadas e sobre as transformações sociais, na medida em que se tratam de identidades construídas na articulação com as crises e transformações econômicas. Como exemplo, há o trabalho de Gutmann (1994) sobre as identidades masculinas no México, além de investigações sociais que deram especial ênfase ao papel do trabalho como um destino incontornável associado ao exercício da masculinidade.

As diferentes pesquisas sobre identidades de gênero, nacionais, regionais e étnicas, em suma, "confirmam a inexistência de uma masculinidade "pura e simples" (p. 77) e apontam que o termo "machismo" merece ser discutido porque não caracteriza a complexidades das relações de gênero na Nossa América. Já no que se refere ao tema das violências, há uma forte produção a respeito dos grupos armados na Colômbia $e$ as masculinidades construídas em contextos de guerra, em diálogo, portanto, com as produções que analisam aspectos como a incorporação da violência na identidade dos jovens e como comportamento de coesão de um grupo social (p. 81). Há, de outra parte, produções mais voltadas à violência doméstica. 
A partir dos anos 90 surgiram pesquisas sobre a saúde sexual e reprodutiva, bem como os fatores de risco para a saúde masculina (p. 85). Em relação aos afetos e sexualidades, Viveros divide a produção em quatro subtemáticas que versam sobre: as práticas e culturas homoeréticas, as práticas e representações da paternidade, os afetos e expressões emocionais de homens heterossexuais $e$ as "masculinidades sem homens" (corpo de mulheres, mas identidades masculinas).

Apesar de não constituir uma preocupação central dos trabalhos nas regióes, as reflexões epistemológicas estão em certas produções destacadas pela autora, como a crítica de Menjívar (2010) quanto aos pressupostos políticos que têm dominado as pesquisas sobre as masculinidades e quanto ao limite do uso de categorias críticas como "masculinidade hegemônica" (p. 93). Para Viveros, contudo, há uma carência importante de trabalhos que busquem conectar os relatos de masculinidades de diferentes áreas geopolíticas.

Sobre as representações culturais das masculinidades, as pesquisas vêm assinalando o bombardeio da imagem de uma identidade masculina viril $e$ heterossexual como "uma ferramenta útil para criar necessidades de consumo diferenciadas segundo o sexo" (p. 96). Por fim, em relação aos espaços de homossocialidade, estes se constituem como lugares identitários nos quais transcorre uma parte da vida dos homens, como os botecos, por exemplo (Jardim, 1992).

Na segunda parte do livro, a autora parte para a análise mais específica do seu objeto empírico e inicia pela separação de um capítulo para cada cor, fazendo jus à proposta do título da obra. Há, então, um capítulo dedicado aos corpos negros e um outro, subsequente, aos benefícios da masculinidade branca. Para o primeiro desafio, Viveros considera importante analisar as respostas dos homens negros frente aos imaginários que os colocam como seres dionísicos, centrados no aproveitamento dos sentidos através do consumo do álcool, da dança e da sexualidade (p. 102). Nesse sentido, utiliza pesquisas realizadas entre 1998 e 
2014, juntamente com uma análise de grupos musicais performativos (como Chocquibtown e Herencia de Timbiquî).

Sobre os estereótipos dos corpos africanos, a autora relembra que, para o Estado colonial, os "poderes sexuais atribuídos aos homens negros ameaçavam a pureza racial e a instituição familiar" (p. 105). Assim, para os grupos dominados sexualmente ou racialmente, há uma identificação posta entre corpo e a natureza (e não com a cultura) tanto no nível do senso comum, como no de especialistas. Nesse sentido, quando estruturadas no racismo, a virilidade é útil à sociedade colonial $e$ pós-colonial apenas na medida em que serve aos interesses da masculinidade hegemônica das classes dominantes.

$\mathrm{Na}$ investigação empírica realizada por Viveros com homens negros, a aptidão para dança aparece como um talento natural das pessoas de "sangue" negro e se constitui como um terreno em que finalmente há uma superioridade em relação aos Brancos. Para a autora, o grupo Chocquitbown possui essa mesma linha de compreensão e celebra o tesão, a potência sexual e o talento para a dança, contribuindo para manter e ressignificar positivamente as representações sobre os homens de Quibdó como quebradores, categoria que a autora utiliza para denominar os homens que estariam sempre prontos para a festa, a dança e o sexo; em oposição, portanto, aos cumplidores, provedores responsáveis.

Em contraponto, há também a compreensão de que a afirmação realizada pelos Brancos "vocês só sabem dançar" é uma desvalorização em completo diálogo com Fanon quando esse descreve: "eu fui construído com o irracional; me atolo no irracional. Irracional até o pescoço" (Fanon, 1952:99 apud Vigoya, 2018:115). Por fim, a autora conclui que, apesar da resistência dos estereótipos sobre os homens negros, o discurso multiculturalista tem permitido que se comece a pensar o negro "aquém" da pele, isto, a partir de uma "subjetividade negra encarnada", com relações com a negridade distintas daquelas postas por quem a estereotipa (p. 124).

Por identificar a completa ausência da análise do caráter racial da experiência branca, Vigoya se põe o desafio de 
demonstrar os limites em entender a branquidade como um lugar social não marcado e invisível, na medida em que isso só seria invisível para aqueles que a habitam (p. 133). Nesse ponto, a autora relembra que, no projeto político republicano, a mestiçagem passou a ser valorizada como característica das novas nações e a moral, ou o "dispositivo da honra," funcionou como alavanca na aspiração social. Os homens próximos à negridade foram, então, percebidos de forma dual: por um lado, como ameaça às mulheres brancas $e$, por outro, como representantes de uma masculinidade viril que daria solidez ao projeto nacional.

Em relação à experiência colombiana, a autora afirma que certos momentos históricos requerem a produção de indivíduos que se proponham a salvar o país da heterogeneidade cultural, racial e sexual, como no caso da eleição do presidente Álvaro Uribe (2002-2010), a quem lhe foram atribuídas as características associadas à masculinidade como autoridade, coerência $e$ obstinação. Assim, na visão de Vigoya, os resultados das políticas públicas construídas pelo governo de Uribe transformaram a diversidade étnico-racial do país em mercadoria de consumo, ao mesmo tempo que impuseram um modelo cultural "branco" (p. 155).

Partindo da compreensão de Scheper-Hughes e Bourgois (2004) sobre a violência como sendo um continuum no qual as categorias de violência estrutural, simbólica, cotidiana e íntima se superpõem ou se alteram, a autora propõe a história da região como um exemplo dessa transposição entre a violência estrutural da colonização e a violência simbólica e doméstica da qual foram vítimas mulheres e homens colonizados (p. 159). Contudo, isso não significa que ela seja um traço distintivo cultural da região $e$ menos ainda que ela se explique pelo machismo, como se fosse uma característica cultural dos homens latino-americanos.

$\mathrm{O}$ que se têm identificado é que a violência aparece como um elemento constitutivo tanto da masculinidade hegemônica, como das subordinadas, de modo que, na América Latina, "muitos homens dominados têm agido como se acreditassem que fortalecer sua masculinidade e sua autoridade sobre as mulheres 
fosse uma parte essencial de sua emancipação" (p. 161). Assim, métodos violentos e repressivos contra movimentos sociais LGBT ou feministas não seriam sinais do poder masculino, mas uma reação ante a perda de poder (p. 171). Soma-se a isso um cenário em que as organizações armadas estão ligadas ao Estado e a violência contra as mulheres se torna uma forma de expressão cometida com fins "pedagógicos", isto é, os feminicídios podem acontecer em cenários em que os autores dos crimes as utilizam, para deslegitimar, desonrar e neutralizar o poder dos homens do grupo inimigo contrário.

Por fim, Viveros estabelece cinco pontos conclusivos para a sua obra. O primeiro deles é sobre como a relação dos homens como o feminismo tem sido uma questão complexa e polêmica, na questão já antes posta por bell hooks: como reconstruir $e$ transformar o comportamento dos homens em práticas feministas? (p. 179). O segundo ponto resume os trabalhos sobre homens $e$ masculinidades realizados na Nossa América a uma crítica ao universalismo e à apresentação de uma grande diversidade de masculinidades que coexistem sob o mesmo território.

No terceiro ponto, a autora retoma os aprendizados sobre branquidade para afirmar que as diferentes masculinidades se constroem em conexão com as mulheres, mas também em relação com os outros homens, com as outras estruturas de dominação $e$ em relação a dinâmicas sociais mais amplas. Em quarto, retomamse as vinculações realizadas entre masculinidades $e$ violência, as quais só passam a ser possíveis a partir da compreensão do gênero como uma estrutura que afeta os corpos e personalidades dos indivíduos, mas que nunca deixa de ser um produto histórico e uma prática produtora de história.

A autora conclui, em seu quinto ponto, que os trabalhos sobre homens e masculinidades na América Latina constituem um campo acadêmico que vem se ampliando, mas ainda são raros aqueles que conectem masculinidades como parte de uma trajetória global. Nesse sentido, seria necessário interligar as histórias não apenas das diferentes cores das masculinidades, conforme Viveros se propôs na obra recém lançada, mas também 
das distintas zonas geopolíticas, relacionando-as aos processos coloniais e neocoloniais e ao contexto do liberalismo econômico mundial. São desafios instigados pela autora que, em toda a sua produção e mais ainda em As cores da masculinidade, fornece chaves teóricas importantíssimas para quem se propor a assumir essa tarefa

\section{Referências bibliográficas}

BOURDIEU, Pierre. La domination masculine. Paris, Seuil, 1998.

CECCHETTO, Fátima Regina. Violência e estilos de masculinidade. Rio de Janeiro, Editora FGV, 2004.

CONNELL, Raewyn. Masculinities. 2. ed. Berkley; Los Angeles, University of California Press, 1995.

FABRE, Clarisse; FASSIN, Éric. Liberté, égalité, sexualités: actualisté politique des questions sexuelles. Paris, Belfond/le Monde, 2003.

FANON, Frantz. Peau noire, masques blancs. Paris, Editions du Seuil, 1952.

GUTMANN, Matthew. Los hijos de Lewis: la sensibilidade antropológica y el caso de los pobres machos. Alteridades, v. 4, n. 7, 1994, pp.9-19 [https://alteridades.izt.uam.mx/index.php/Alte/article/view/594 - acesso em: 09 out. 2020].

JARDIM, Denise Fagundes. Espaço social e autossegregação entre homens: gostos, sonoridades e masculinidades. Cadernos de Antropologia, Porto Alegre, n.7, 1992, pp.28-41.

KIMMEL, Michael. Los estúdios de masculinidade: uma introducción. In: ARMENGOL, J; CARABÍ, À. (org.), La masculinidade a debate. Barcelona, Icaría, 2008, pp.15-32.

MENJÍVAR, Mauricio. La masculinidad a debate. Costa Rica, FLACSO, 2010.

SCHEPER-HUGHES, Nancy; BOURGOIS, Philippe. Introduction: Making Sense of Violence. In: SCHEPER-HUGHES, N; BOURGOIS, Philippe (org.). Violence in war and peace: na anthology. Padstow, Cornwall, Blackwell Publishing, 2004, pp.1-32. 